\title{
EDITORIAL
}

\section{Advances in Mobile Learning Educational Research (A.M.L.E.R.): Mobile learning as an educational reform}

\section{Editor-in-Chief: Dr. Stamatios Papadakis}

Faculty of Education \& Department of Preschool Education, The University of Crete, Greece

\section{Check for updates}

Correspondence to: Stamatios Papadakis, Faculty of Education \& Department of Preschool Education, The University of Crete, Greece;

E-mail: stpapadakis@uoc.gr

Received: March 29, 2021;

Accepted: March 30, 2021;

Published: March 30, 2021

Citation: Papadakis, S. (2021). Advances in Mobile Learning Educational Research (A.M.L.E.R.): Mobile learning as an educational reform. Advances in Mobile Learning Educational Research, 1(1): 1-4. https://doi.org/10.25082/AMLER.2021.01.001

Copyright: () 2021 Stamatios Papadakis. This is an open access article distributed under the terms of the Creative Commons Attribution License, which permits unrestricted use, distribution, and reproduction in any medium, provided the original author and source are credited.

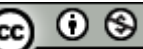

Children and students of all ages are in the midst of a vast, unplanned experiment, surrounded by digital technologies that were not available but five years ago (Hirsh-Pasek et al., 2015). Mobile touchscreen technologies revolutionize the interactive digital experiences of young children and students (Hwang et al., 2015). Owing to the growing inclusion of touchscreens, the mouse keyboard and desktop graphical interface days are numbered (Papadakis \& Kalogiannakis, 2020).

Children and students, especially young, explore and learn with mobile devices in natural ways (touch, repeat, trial, and error) (Cohen et al., 2011). The reason is that touchscreen devices (tablets) are designed so that even noticeably young users can use them efficiently (Kucirkova, 2016). Early research findings show that children younger than two years old can play and learn using mobile devices and multitouch displays and that children as young as two would naturally interact with a touchscreen; in the same way, they will use instincts to play with a new toy (Statista, 2021). For instance, preschool children do not need to develop the manual handling skills to use a separate keyboard and mouse required by general-purpose computers to gain access to interactive content explicitly designed for them (Papadakis, 2020a). At its best, touchscreen technology offers a mode of interactive experience that mirrors the child's natural constructivist learning. Ideally, smart devices accompanying applications (Apps) can create exciting and effective learning environments for learning and instruction in educational settings (Goodwin, 2012). Developers are increasingly creating educational Apps. Mathematics and literacy Apps are the most popular categories of Apps (Statista, 2021).

Currently, there are few examples of well-designed educational Apps for young children and students (Hirsh-Pasek et al., 2015). The selection of the right App is essential as it can make the difference between the 'digital babysitter' and the tool to support children's learning and development (Goodwin, 2013). As many of the self-proclaimed educational Apps are very entertainment-oriented for several reasons, they lack an educational impact on child cognitive development. Although some parents are advanced and knowledgeable technology users themselves, this does not mean that they necessarily understand the full implications of young children's I.C.T. products and services (Ebbeck et al., 2016). At this point, choosing the appropriate technologies such as Apps that facilitate active and creative use by children is becoming bigger and bigger for both parents and educators. As not all Apps are of the same quality, it is also important to note; cost does not necessarily correlate with quality (Bouck et al., 2016). Given the absence of an industry-standard or an official rating system for children's Apps, websites or blogs are often consulted when choosing Apps by parents and educators (Papadakis et al., 2020). However, this selection method is problematic too. The reason is that most of those blogs and websites use a methodology for assessing 'educational' Apps for children, which is lacking in terms of quality and does not meet age-appropriate and other pedagogical standards.

Papadakis (2020b) study identified 11 articles describing two different approaches to evaluate educational Apps after selecting the eligible studies. Six studies present a rubric, and five studies present a checklist. Additionally, this study also identified seven nonscientific-based tools. Four web sources present a rubric, while three web sources present a checklist and one rubric as a hybrid as it combines a rubric's content completeness into a single checklist.

In general, this study's results revealed that the existing body of scientific-based tools is smaller than expected compared to the number of research papers published about the low quality of educational Apps. During this review, evaluation tools that are available for free on various websites were also found. Although these sources might be used as "a first step" in educational App evaluation, they are not based on scientific evidence and significantly omit important App assessment aspects. Only one freely available tool (K.I.D.M.A.P.) can 
be considered comprehensive enough to evaluate educational Apps. The other six tools have limitations and can be considered inadequate tools in terms of their evaluation power.

Martens et al. (2018) state that there is no easy way to determine what constitutes an excellent educational App. They argue that parents and educators should look out for "lack of quality" characteristics such as the presence of advertisements and in-app purchases, poor design, privacy concerns, etc. The analysis of the quality criteria used by the scientific and non-scientific tools revealed that the tools use different sets of elements to evaluate the educational Apps. This wide diversity of criteria does not allow for the formation of a clear pattern. This problematic situation is found in many studies. For instance, in his study, Rosell-Aguilar (2017) found that a few criteria are standard among most frameworks. Petri \& von Wangenheim (2016) describe the same problem in their attempt to find educational games' evaluation tools. Identifying the various tools' standard features was demanding, as different terms were used for the same concept in different tools. For instance, Lee \& Cherner (2015) rubric used the term "Value of errors," while other rubrics for the same characteristic used the term "Feedback." Other rubrics used the term "Personal preferences" instead of "Customization."

In most cases, the characterization of the various elements did not precisely match. Kathy Hirsh-Pasek and her co-researchers state that an educational App must foster active, engaged, meaningful, and socially interactive learning. Lee \& Cherner (2015) rubric to homogenize further the initial huge number of evaluative dimensions in the various tools were used. Summarizing, criteria that refer to the "Design" section of the Apps such as "The Screen Design," "Navigation," "Learner Control" were found in all scientifically-based tools. This is considered necessary, as Marsh et al. (2015) state that there is evidence that suggests that Apps of appropriate quality and design promote a wide range of play and creativity for preschoolers (p.34). The same researchers state that creativity is "defined as the production of original content and evidence of diverse forms of thinking, both often present in young children's play and everyday uses of technology" (Marsh et al., 2015). Furthermore, other essential designs and content elements such as the "Content Appropriateness," the "Value of Errors" (e.g., feedback), the "Higher-order Thinking Skills," the "Ease of Use" and the "Cultural Sensitivity" (e.g., bias-free) were found in most tools. This is a critical issue to consider as, since the era of personal computers, researchers recognized the need for educational software that is easily navigated, without errors in design, and with a higher level of parametrization that is intuitive and engaging for students of all ages (see Haugland Developmental Software Scale, Haugland, 1999).

Supporters of introducing creative thinking and problem-solving in education argue for systematic reform to primary and secondary schools that encompass modern technology educational tools demanded of students in the twenty-first century. In this context, we cannot insulate children from technology, but we need to ensure that they are not harmed in any way by it (Ebbeck et al., 2016). As Parette et al. (2010) state concerning specific technology applications available to young children, the issue is not whether technology should be considered and used in education settings but how and whether it makes a difference in children's learning and development. Additionally, research supports that the classroom environment is rich in students' connections and opportunities to engage actively in Science, Technology, Engineering, and Mathematics (S.T.E.M.) activities (MacDonald et al., 2020). Nowadays, there are numerous mobile educational tools available for children to engage them in S.T.E.M. activities such as visual block-based environments (e.g., ScratchJr), online environments (e.g., Code.org), robotic devices (e.g., Bee-bot), and of course, unplugged activities (Dorouka et al., 2020). Discussion of these aspects will be a welcome feature on the pages of the journal.

The journal Advances in Educational Research and Evaluation is a peer-reviewed openaccess journal aimed to be a medium for discussing a wide range of international educational experiences and assessment techniques. The journal intends to publish high-quality articles, the scope of which includes but is not limited to topics mentioned in this editorial. With the support of an international team of educational scholars who kindly volunteered to serve on the editorial board, the journal is set to adhere to the highest publishing ethics standards.

In conclusion, we welcome researchers worldwide to publish research papers on mobile technology's pedagogical uses, where the focus is broad enough to be of interest to a broader education community. We also welcome systematic review papers and meta-analyses that include straightforward research questions, a framework of analysis, and conclusions that reflect the paper's aims. Furthermore, studies that focus on teaching and learning in science, technology, engineering, and mathematics (S.T.E.M.) and educational robotics; studies that address specific challenges in improving students' achievement, approaches used to motivate and engage students, and lessons learned from changes in curriculum and instruction based on educational technology in general. 


\section{References}

Bouck, E.C., Satsangi, R., \& Flanagan, S. (2016). Focus on inclusive education: evaluating apps for students with disabilities: supporting academic access and success. Childhood Education, 92(4), 324-328.

https://doi.org/10.1080/00094056.2016.1208014

Cohen, M., Hadley, M., \& Frank, M. (2011) Young Children, Apps \& iPad, Michael Cohen Group, New York.

Dorouka, P., Papadakis, S., \& Kalogiannakis, M. (2020). Tablets and apps for promoting robotics, mathematics, S.T.E.M. education and literacy in early childhood education. International Journal of Mobile Learning and Organisation, 14(2), 255-274. https://doi.org/10.1504/IJMLO.2020.106179

Ebbeck, M., Yim, H.Y.B., Chan, Y., \& Goh, M. (2016). Singaporean parents' views of their young children's access and use of technological devices. Early Childhood Education Journal, 44(2), 127134. https://doi.org/10.1007/s10643-015-0695-4

Goodwin, K. (2012). Use of Tablet Technology in the Classroom, N.S.W. Curriculum and Learning Innovation Centre. Retrieved from http://www.tale.edu.au

Goodwin, K. (2013). iPads \& Young Children: An Essential Guide for Parents. Retrieved from http://goo.gl/ZYPiaa

Haugland, S. (1999). Computers and young children: the newest software that meets the developmental needs of young children. Early Childhood Education Journal, 26(4), 245-254. https://doi.org/10.1023/A:1022915706904

Hirsh-Pasek, K., Zosh, J.M., Golinkoff, R.M., Gray, J.H., Robb, M.B., \& Kaufman, J. (2015). Putting education in "educational" apps lessons from the science of learning. Psychological Science in the Public Interest, 16(1), 3-4. https://doi.org/10.1177/1529100615569721

Hwang, G.J., Wang, S.Y., \& Lai, C.L. (2015). Seamless flipped learning - a mobile technology enhanced flipped classroom with effective learning strategies. Journal of Computers in Education, 2(4), 449-473. https://doi.org/10.1007/s40692-015-0043-0

Kucirkova, N. (2016). iRPD - a framework for guiding design-based research for iPad apps. British Journal of Educational Technology, 48(2), 598-610. https://doi.org/10.1111/bjet.12389

Lee, C.Y., \& Cherner, T.S. (2015). A comprehensive evaluation rubric for assessing instructional apps. Journal of Information Technology Education Research, 14: 21-53. https://doi.org/10.28945/2097

MacDonald, A., Huser, C., Sikder, S., \& Danaia, L. (2020). Effective early childhood S.T.E.M. education: Findings from the little scientists evaluation. Early Childhood Education Journal, 48(3), 353-363. https://doi.org/10.1007/s10643-019-01004-9

Marsh, J. Plowman, L. Yamada-Rice, D. Bishop, J.C. Lahmar, J. Scott, F. Davenport, A. Davis, S. French, K. Piras, M. Thornhill, S. Robinson, P., \& Winter, P. (2015). Exploring play and creativity in preschoolers' use of apps: report for early years practitioners. Retrieved from www.techandplay.org/reports/TAP_Final_Report.pdf

Martens, M., Rinnert, G.C., \& Andersen, C. (2018). Child-centered design: developing an inclusive letter writing app. Frontiers in Psychology, 9, 2277. https://doi.org/10.3389/fpsyg.2018.02277

Papadakis, S. (2020a). Apps to Promote Computational Thinking Concepts and Coding Skills in Children of Preschool and Pre-Primary School Age. In Mobile Learning Applications in Early Childhood Education (pp. 101-121). I.G.I. Globa. https://doi.org/10.4018/978-1-7998-1486-3.ch006

Papadakis, S. (2020b). Tools for evaluating educational apps for young children: a systematic review of the literature. Interactive Technology and Smart Education, Vol. ahead-of-print No. ahead-of-print. https://doi.org/10.1108/ITSE-08-2020-0127

Papadakis, S., \& Kalogiannakis, M. (2020). A research synthesis of the real value of self-proclaimed mobile educational applications for young children. Mobile learning applications in early childhood education, 1-19. https://doi.org/10.4018/978-1-7998-1486-3.ch001

Papadakis, S., Vaiopoulou, J., Kalogiannakis, M., \& Stamovlasis, D. (2020). Developing and Exploring an Evaluation Tool for Educational Apps (E.T.E.A.) Targeting Kindergarten Children. Sustainability, 12,4201 . https://doi.org/10.3390/su12104201

Parette, H. P., Quesenberry, A. C., \& Blum, C. (2010). Missing the boat with technology usage in early childhood settings: a twenty-first century view of developmentally appropriate practice. Early Childhood Education Journal, 37(5), 335-343. https://doi.org/10.1007/s10643-009-0352-X

Petri, G., \& von Wangenheim, C.G. (2016). How to evaluate educational games: a systematic. Journal of Universal Computer Science, 22(7), 992-1021.

Rosell-Aguilar, F. (2017). State of the app: a taxonomy and framework for evaluating language learning mobile applications. CALICO Journal, 34(2), 243-258. 
Sharkins, K.A., Newton, A.B., Albaiz, N.E.A., \& Ernest, J.M. (2015). Preschool children's exposure to media, technology, and screen time: perspectives of caregivers from three early childcare settings. Early Childhood Education Journal, 44(5), 437-444. https://doi.org/10.1007/s10643-015-0732-3

Statista. (2021). Worldwide mobile education app downloads from 1st quarter 2017 to 1 st quarter 2020 , by platform. Retrieved from

https://www.statista.com/statistics/1128262/mobile-education-app-downloads-worldwide-platfor ms-millions/ 